\title{
Antecedents And Consequences Of Job Satisfaction: Testing A Comprehensive Model Using Integrated Methodology
}

W. Kevin Baker, (Email: baker@roanoke.edu), Roanoke College

\begin{abstract}
This study examines the key antecedents and two important consequences of job satisfaction in a comprehensive framework by utilizing integrated methodologies. This involves combining meta-analytic techniques with structural equation modeling. The antecedents represent theoretical perspectives that indicate workplace influences including task characteristics, social information processing, and dispositional perspectives. The consequences are the withdrawal behaviors of absenteeism and turnover. The results indicate all three perspectives are supported to varying degrees with multiple antecedents impacting job satisfaction. However, the dispositional variables maintain the greatest overall impact. Interestingly, job satisfaction had little impact on the progression of withdrawal behaviors. Although job design and leadership behaviors impact job satisfaction, management needs to reconsider hiring and selection practices as they relate to the dispositional aspects of potential employees.
\end{abstract}

\section{Introduction}

$\mathscr{J}$ ob satisfaction has been one of the more researched affective measures in the literature. Every year organizations like the Conference Board measure the overall job satisfaction of American workers. Our preoccupation with job satisfaction can be attributed to its hypothesized importance in relation to various employee workplace responses. Several competing theoretical approaches have been advanced that attempt to describe the antecedents to job satisfaction. Unfortunately, these models have not been compared in a study that examined their concurrent impact in a comprehensive framework across diverse samples. Integrating meta-analytic techniques with structural equation modeling can achieve this objective. This technique has been used to examine the theoretical models that explain organizational commitment (Eby, Freeman, Rush, \& Lance, 1999) and would be an equally effective method to examine job satisfaction. In addition, this study will add further refinements to the technique to increase precision (i.e. correcting non-normality and incorporating measurement error into the analysis).

Several sets of antecedent variables are used to represent important aspects of the theoretical perspectives regarding the predictors of job satisfaction. These variables correspond to the task characteristics, dispositional, social information processing, and dual-attachment approaches. This will help to separate the effects that the various antecedents have on job satisfaction and the concurrent impact the approaches have on job satisfaction.

The withdrawal behaviors of absenteeism and turnover will also be examined as consequences of job satisfaction. Additionally, the inclusion of both absenteeism and turnover will allow the progression of withdrawal to be examined and the role that job satisfaction plays in this progression.

\section{Job Satisfaction}

The construct of job satisfaction is generally defined as a positive emotional state that reflects an affective response to the job situation (Locke, 1976). The focus is task-oriented and short-term in nature (Mowday, Porter, \& 
Steers, 1982). Several general perspectives have been examined that explain job satisfaction with all of these approaches demonstrating some degree of supporting evidence. However, there has been no concurrent testing of these competing models in a comprehensive path model.

\section{Theoretical Approaches To Job Satisfaction}

Task characteristics approach: This perspective proposes that the task characteristics are related to employee attitudes and describes jobs by the five perceived core dimensions of autonomy, feedback from the job, job variety, task identity, and task significance (Hackman \& Oldham, 1975). These five dimensions will further impact the three mediating psychological states of experienced meaningfulness, experienced responsibility, and knowledge of results. A higherorder need, referred to as growth need strength (GNS), has been hypothesized to be a moderator variable. However, research regarding the mediating states and GNS have been weak and inconsistent in support of these concepts (Walsh, Taber, \& Beehr, 1980; Seers \& Graen, 1984; Hogan \& Martell, 1987). Recent studies continue to support task characteristics directly impacting job satisfaction in diverse samples (Bhuian, Al-Shammari, \& Jefri, 1996; Ting, 1996; Reiner \& Zhao, 1999; Bhuian \& Menguc, 2002).

Social information processing approach: This situational approach has been proposed as an alternative to the task characteristics approach (Salancik \& Pfeffer, 1978). It rests on the basic premise that job attitudes are determined by social cues processed from the work environment. The association between job characteristics and job attitudes results from the fact that both are the consequences of the prevailing normative and informational structure of the work setting (Pfeffer, 1982). Early validation for the social information processing theory was mostly from laboratory studies (White \& Mitchell, 1979; Leigh, Lucas, \& Woodman, 1988). There has been a degree of recent support for this perspective in using leadership as the normative or information source. These studies found that leadership styles or behaviors impact job satisfaction (Landeweerd \& Boumans, 1994; Dubinsky, Yammarino, Jolson, \& Spangler, 1995; Jones, Kantak, Futrell, \& Johnston, 1996; de Vries, Roe, \& Taillieu, 1998).

Dispositional approach: The dispositional approach has garnered renewed interest in recent years. This perspective indicates that the individual possesses relatively stable unobservable mental states such as needs or attitudes that will impact their perceptions and behavior (Staw \& Ross, 1985). The approach indicates that work attitudes are formulated from internal states. The essence of the approach is that individuals possess stable traits that significantly influence their affective and behavioral reactions to organizational settings (Davis-Blake \& Pfeffer, 1989). Employees will process information in such a way to be consistent with their internal states (Staw, Bell, \& Clausen, 1986). Research has tended to indicate a degree of temporal stability in dispositions, as well as cross-situational stability (Staw \& Ross, 1985; Steel $\&$ Rentsch, 1997). Recent studies continue to support dispositions and their impact on job satisfaction including intrinsic motivation (Savery, 1996; Lu, 1999; Schonfeld, 2000), positive/negative affectivity (Connolly \& Viswesvaran, 2000; Simmons, Nelson, \& Neal, 2001), self-esteem (Costa \& McCrae, 1994), and need for achievement (Mannheim, Baruch, \& Tal, 1997).

Combined or integrated approach: Griffin, Bateman, Wayne, and Head (1987) combined the task characteristics model with the social information processing model. This viewpoint proposes that job enrichment and social cues combine to influence perceptions and attitudes. A laboratory study conducted by the authors supported the perspective. This perspective is similar to an earlier viewpoint proposed by Graen and Ginsburgh (1977). This approach combined both task characteristics with leader-member exchange (Graen, Novak, \& Sommerkamp, 1982). However, these combined models limit the impact of dispositional variables. This study will include these variables in a more thorough examination.

\section{Outcomes of Job Satisfaction}

Two important outcomes of job satisfaction will be explored - absenteeism and turnover. Job satisfaction has been examined extensively as a predictor of employee absenteeism in the literature, including explanatory models (Brooke \& Price, 1989). Meta-analytic studies concluded the relationship was a relatively weak negative one (Hackett \& Guion, 1985; Farrell \& Stamm, 1988). Conversely, a Scott and Taylor (1985) meta-analysis discovered a strong negative relationship between overall job satisfaction and the absence frequency measure. 
The other outcome examined is turnover. Job satisfaction has been investigated as an antecedent to separation in several major early turnover models (Price \& Mueller, 1981; Bluedorn, 1982). The results from empirical tests have pointed to a modest negative relationship between job satisfaction and turnover (Price, 1977; Mobley, Griffeth, Hand, \& Meglino, 1979). Job satisfaction has also been found to have a significant correlation with turnover in meta-analytic findings (Cotton \& Tuttle, 1986).

\section{Progression of Withdrawal Behaviors}

An examination of the literature regarding employee withdrawal revealed that the relationship among withdrawal behaviors followed three historical theoretical viewpoints (Chadwick-Jones et al., 1982). These viewpoints presented the confirmatory evidence but did not explain the process underlying their models. The first viewpoint indicated that withdrawal behaviors were progressive (Herzberg et al., 1957). Individuals who leave the organization progressed from absenteeism to separation. This implies a positive relationship between absenteeism and turnover. A second viewpoint proposed that absenteeism and turnover were viable alternatives to each other. This suggested absenteeism and turnover were perceived as interchangeable responses to the work setting by the employees (Benson \& Pond, 1987). The resulting relationship between absenteeism and turnover would be negative. The final viewpoint indicated that withdrawal behaviors may share common causes, but they were not necessarily progressive (Benson \& Pond, 1987). This null position proposes no relationship between these two variables.

Past research has found varying degrees of support for all three of these positions (Mowday et al., 1982; Wolpin $\&$ Burke, 1985). However, research into the progression of withdrawal behaviors has been problematic in several respects. Most of the studies have failed to address causality by utilizing a path model and the models have lacked a comprehensive framework. The inclusion of a more complete set of antecedents would give insight into other variables that impact withdrawal directly or indirectly through job satisfaction. Finally, measurement error and nonnormality in absenteeism and turnover measurement needs to be corrected (Watson, 1981; Wolpin \& Burke, 1985).

\section{Methods}

The integration of meta-analysis and structural equation modeling (SEM) has the ability to examine a comprehensive model by combining the results of independent studies while maintaining causal inferences. Meta-analysis combines the results of independent studies by merging bivariate effect sizes. However, meta-analyses will not control other variables or establish causality. This weakness can be overcome by combining meta-analysis with SEM. Structural equation modeling refers to a technique that is used to examine the causal relationships between multiple exogenous and endogenous variables placed in a path model reflecting a theoretical foundation (Hayduk, 1987). A major difficulty of SEM is related to its application. Most studies using this form of analysis have explored only restricted pieces of the job satisfaction process. This is generally due to the difficulty of collecting the necessary data and/or prohibitive questionnaire length involved in testing a comprehensive model. The generalizability of the results can also be a concern considering that the samples are usually limited in scope, size, and diversity. Integrating meta-analysis with structural equation modeling will result in a synergistic relationship that will eliminate the shortcomings of each of the individual techniques as applied to comprehensive models. The use of SEM can partial out the effects of common cause variables to give a better indication of the true relationship between the two variables, thus eliminating spurious relationships. Unlike meta-analysis, it will address the issue of causality directly. Meta-analysis will add generalizability by cumulating the results from various samples from diverse settings. Additionally, this combining of studies will greatly increase the sample size and power. Thus, the need for an excessively lengthy questionnaire is eliminated and this integration allows for a comprehensive model to be adequately tested.

\section{Analysis}

The study investigates the antecedents and consequences of job satisfaction by combining effect sizes across samples and integrating the results into a structural equation model. The paths diagrammed in the model will obtain their theoretical foundation from previous research that has investigated causal relationships. Initially, all paths were included in a just-identified model and the insignificant paths were eliminated using a theory-trimming technique (Pedhazur, 1982). 
The effect sizes (r-index) were accumulated across the various studies by conversion into Z-scores and weighting them by sample size (Cooper, 1989). Measures that had inherent range restriction problems (i.e., turnover proportions of stayers verses leavers) were corrected. These point-biserial turnover correlations were corrected for variance restriction and converted to biserial correlations (Steel, Shane, \& Griffeth, 1990). This involved calculating an ecological base rate as a basis for the correlation corrections. In the studies examined, the cumulative turnover percentage or ecological base rate was $2.45 \%$ in a total sample size of 19,081 . The average sample size in the bivariate relationships was 4,391 . The sample size utilized in the model was 500 due to power considerations and because chi-square statistics have problems with larger sample sizes (Hayduk, 1987).

Table 1 Meta-Analysis Bivariate Correlations

\begin{tabular}{|c|c|c|c|c|c|c|c|c|c|c|c|c|}
\hline Variable Name & 1 & 2 & 3 & 4 & 5 & 6 & $\overline{7}$ & 8 & 9 & 10 & 11 & 12 \\
\hline Job Satisfaction & 1.00 & & & & & & & & & & & \\
\hline Absenteeism & .14 & 1.00 & & & & & & & & & & \\
\hline Turnover & .19 & .31 & 1.00 & & & & & & & & & \\
\hline Autonomy & .35 & -.10 & -.09 & 1.00 & & & & & & & & \\
\hline Feedback & .29 & -.02 & -.12 & .35 & 1.00 & & & & & & & \\
\hline Job Variety & .31 & -.04 & -.10 & .43 & .33 & 1.00 & & & & & & \\
\hline Task Identity & .24 & -.08 & -.07 & .41 & .41 & .25 & 1.00 & & & & & \\
\hline Task Significance & .28 & -.03 & .10 & .34 & .34 & 41 & .26 & 1.00 & & & & \\
\hline Initiating Structure & .28 & -.11 & .17 & -.06 & .20 & .07 & .04 & .11 & 1.00 & & & \\
\hline Consideration & .52 & -.14 & -.13 & .29 & .28 & .16 & .13 & .14 & .50 & 1.00 & & \\
\hline Need for Achievement & .43 & -.01 & -.14 & .12 & .08 & .01 & -.04 & .02 & .09 & .03 & 1.00 & \\
\hline Motivation & .41 & -.20 & -.22 & .27 & .29 & .31 & .20 & .32 & .04 & .30 & .01 & 1.00 \\
\hline
\end{tabular}

An overall effect size was derived that reflected the relationship between all the variables included in the study. Table 1 shows the effect sizes ( $r$ ) for all bivariate relationships. The average standard deviations for the measures were also calculated and weighted by sample size (Table 2). In the case of the JDS instrument, the norms set forth by Hackman and Oldham (1975) were used. The effect sizes and standard deviations were placed into a covariance matrix as input for structural equation analysis (Tett \& Meyer, 1993). The search procedure for the meta-analysis consisted of examining entries in periodical and database headings that follow key words that reflected the variables of interest.

Table 2: Meta-Analysis Weighted Standard Deviations And Reliabilities

\begin{tabular}{l|cc|cc}
\hline Variable Name & N & S.D. & N & Reliability \\
\hline Absenteeism $^{1}$ & 3564 & 2.50 & -- & .95 \\
Autonomy $^{1}$ & -- & 1.17 & 16117 & .71 \\
Feedback $^{1}$ & -- & 1.21 & 15586 & .73 \\
Job Satisfaction $^{1}$ & -- & 1.07 & 30568 & .84 \\
Job Variety $^{1}$ & -- & 1.22 & 16087 & .74 \\
Leader Consideration $^{\text {Initiating Structure }}$ & 7886 & 2.72 & 7820 & .82 \\
Motivation $^{1}$ & 9298 & 2.11 & 10052 & .80 \\
Need for Achievement $^{1}$ & -- & 6894 & .75 \\
Task Identity $^{1}$ & 4022 & 2.66 & 7921 & .75 \\
Task Significance $^{1}$ & -- & 1.25 & 12589 & .71 \\
Turnover $^{\text {I }}$ & -- & 1.09 & 8725 & .66 \\
\hline Std. & -- & .42 & -- & .95 \\
\hline
\end{tabular}

The path model was analyzed with a structural equation model using Lisrel (Joreskog \& Sorbom, 1993). Standardized path coefficients were utilized to estimate the parameters of the model. This allowed direct comparisons on the strength of the relationship between variables in the path model regardless metrics. The effect sizes were corrected for 
measurement error. This was accomplished by incorporating a percentage of error variance into the proper matrices. This estimate of error variance reflected the average reliability of the measurement instruments weighted by sample size (Table 2). For absenteeism and turnover, only $5 \%$ error variance was assumed to account for data entry or coding errors.

\section{Measuring Instruments}

There needed to be consistency in measuring instruments to appropriately utilize a meta-analysis technique. Since standardized path coefficients and not metric coefficients were employed, those instruments that had established convergent validity were utilized. As discussed earlier, several instruments (Faces, JDI, JDS, MSQ, and INDSALES) have demonstrated convergent validity for the measurement of job satisfaction. The antecedents of job satisfaction consisted of several well-documented instruments with established validities and reliabilities. Task characteristics were measured with three instruments with convergent validity (Brief \& Aldag, 1978) including Yale Job Inventory or YJI (Hackman \& Lawler, 1971), Job Diagnostic Survey or JDS (Hackman \& Oldham, 1975), and Job Characteristics Inventory or JCI (Sims, Szilagyi, \& Keller, 1976).

Leader consideration and initiating structure measurement instruments include Fleishman's Supervisory Behavioral Description Questionnaire (Fleishman, 1953) and the Leader Behavior Description Questionnaire Form XII (Stogdill, 1963). Motivation is assessed by the JDS measure (Hackman \& Oldham, 1975) and Yale Job Inventory or YJI (Hackman \& Lawler, 1971). Need for achievement was measured by the Manifest Needs Questionnaire or MNQ (Steers \& Braunstein, 1976).

The consequences of job satisfaction were absenteeism and turnover. Absenteeism was measured by absence frequency data. Vroom (1964) indicated that absence frequency was more strongly related to satisfaction than absence duration. This rested on the basic premise that short-term absences were more at the discretion of the employee as opposed to long-term absences that were often beyond the individual's control (i.e. illness, injury). Finally, turnover measures were corrected for range restriction.

\section{Research Propositions}

\section{Prediction Of Job Satisfaction}

These theoretical perspectives that specify the antecedents of job satisfaction have all had some degree of confirmatory evidence. The oldest of these viewpoints is the task characteristics approach and recent studies continue to support this viewpoint (Zeffane, 1994; Ting, 1996; Bhuian \& Menguc, 2002). The social information processing perspective receives support primarily from social cues derived from leadership. Recent studies have supported the impact of leadership on satisfaction (Jones, Kantak, Futrell, \& Johnston, 1996; de Vries, Roe, \& Taillieu, 1998). The disposition approach or perspective also has confirmatory evidence from numerous recent studies (Judge \& Larsen, 2001).

It is conceivable that across samples all of these models impact job satisfaction. This coincides with the integrated or the dual-attachment approach (Graen, 1976). This approach described three domains that interact to define an individual's organizational role including the physical/technological, interpersonal/social, and personal domains. The physical-technological domain is represented by task characteristics. The exchange or interaction with supervisors or leaders will serve to represent the social influences or cues of the interpersonal-social domain (Seers \& Graen, 1984). Previous research has found social cues given by supervisors to subordinates had a significant effect on altering their perceptions and attitudes (Griffin, 1983). The personal domain has usually been represented by growth need strength that was considered a moderator in the task characteristics approach. Unfortunately, the findings regarding growth need strength have been inconclusive and a study by Tiegs, Tetrick, and Fried (1992) found no moderator effect in a sample of 6,405. This study will represent the personal domain more thoroughly by the inclusion of dispositional aspects. Two important dispositional variables that are related to organizational success are need for achievement and intrinsic motivation. Both of these variables are causally related to job satisfaction (Mannheim, Baruch, \& Tal, 1997; Lu, 1999; Schonfeld, 2000). 
Hypothesis 1: There is a significant direct effect from task characteristics, social information processing, and dispositional factors to job satisfaction.

The impact that these variables will have on job satisfaction will vary. Job design and leadership variables reflect situational aspects that are not likely to maintain the impact of the dispositional variables. Dispositional aspects should have more consistency across settings. This stability and cross-situational consistency has been supported by previous research (Staw \& Ross, 1985). The influence of task characteristics and leadership will have less overall impact due to their situational nature. Task characteristics are known and accepted after the employee has completed the socialization procedure. Tenured employees develop expectations regarding these task characteristics, and it is unlikely that organizational changes are significant enough to alter these perceptions. Additionally, job descriptions are defined for virtually all organizational positions and rarely undergo significant alteration. Leadership's impact is likely mitigated by the importance of factors that serve to replace its influence across samples. These are referred to as substitutes and/or neutralizers for leadership that occur in subordinate, task, and organizational characteristics. Kerr and Jermier (1978) indicated that subordinates with experience, professional orientations, or indifference to organizational rewards have less need for leadership. Tasks that are structured and routine, provide feedback, or are intrinsically satisfying substitute for leadership. Finally, organizations that are exemplified by cohesive work groups, formalization, inflexibility, leader isolation, or low leader positional power will act as a substitute or neutralize leadership efforts. In the same vein, organizations with strong cultures will have less need for direct leadership since workers internalize corporate beliefs and values.

Hypothesis 2: The direct effects from the dispositional variables are greater than the direct effects from task characteristics and leadership factors.

\section{Outcomes of Job Satisfaction}

Two important consequences of job satisfaction are absenteeism and turnover. As previously mentioned, there are three viewpoints concerning the progression of withdrawal (Benson \& Pond, 1987). There may a progressive aspect from absenteeism to separation indicating a positive relationship between absenteeism and turnover. This apparent progression of withdrawal appears to be the most accepted in the literature. The second viewpoint considers absenteeism as being perceived by the employee as an alternative behavior to separation. In this case, the relationship would be negative. The final viewpoint suggests there is no relationship between the variables. There has been some limited support for all of these viewpoints in past empirical studies (Gupta \& Jenkins, 1982; Wolpin \& Burke, 1985; Rosse, 1988). This study will define a process for a positive progression implicating the influence of job satisfaction on absenteeism and turnover. This could help account for the often inconsistent relationship between absenteeism and turnover (Clegg, 1983). Absenteeism models proposed that job satisfaction is a key predictor of absenteeism and research findings have causally linked job satisfaction to absenteeism (Hackett \& Guion, 1985; Brook \& Price, 1989). Additionally, turnover models viewed satisfaction as an important influence on separation (Price, 1977; Price \& Mueller, 1981). Unfortunately, these studies did not test both absenteeism and turnover concurrently.

This study proposes that in the short run, job dissatisfaction can lead to increased absences. This can be seen as a response by the worker to compensate for feelings of dissatisfaction. In the long run, it is unlikely that dissatisfaction will necessarily result in turnover. This is supported in the literature in that job satisfaction is generally not a significant predictor of turnover (Clegg, 1983; Johnston, Varadarajan, Futrell, \& Sager, 1987). Overall, a worker may experience dissatisfaction and increase absences, but it does not mean they will leave in the long run. This is due to the fact that a worker will build up investments in the organization that makes it difficult to leave. These investments include tenure, salary, promotions, peer cohesion, community ties, and family commitments. These investments are cognitively balanced against the experienced dissatisfaction. This will delineate job satisfaction as a significant predictor of absenteeism, not turnover. When absenteeism and turnover are both included in the path model, the relationship between satisfaction and turnover will be indirect through absenteeism. The research propositions that have been hypothesized are illustrated in Figure 1.

Hypothesis 3: Job satisfaction has a direct effect (DE) on absenteeism.

Hypothesis 4: Job satisfaction has only an indirect effect (IE) on turnover through absenteeism. 
Hypothesis 5: Absenteeism has a significant direct effect (DE) on turnover reflecting a withdrawal progression.

Figure 1 Hypothesized Model

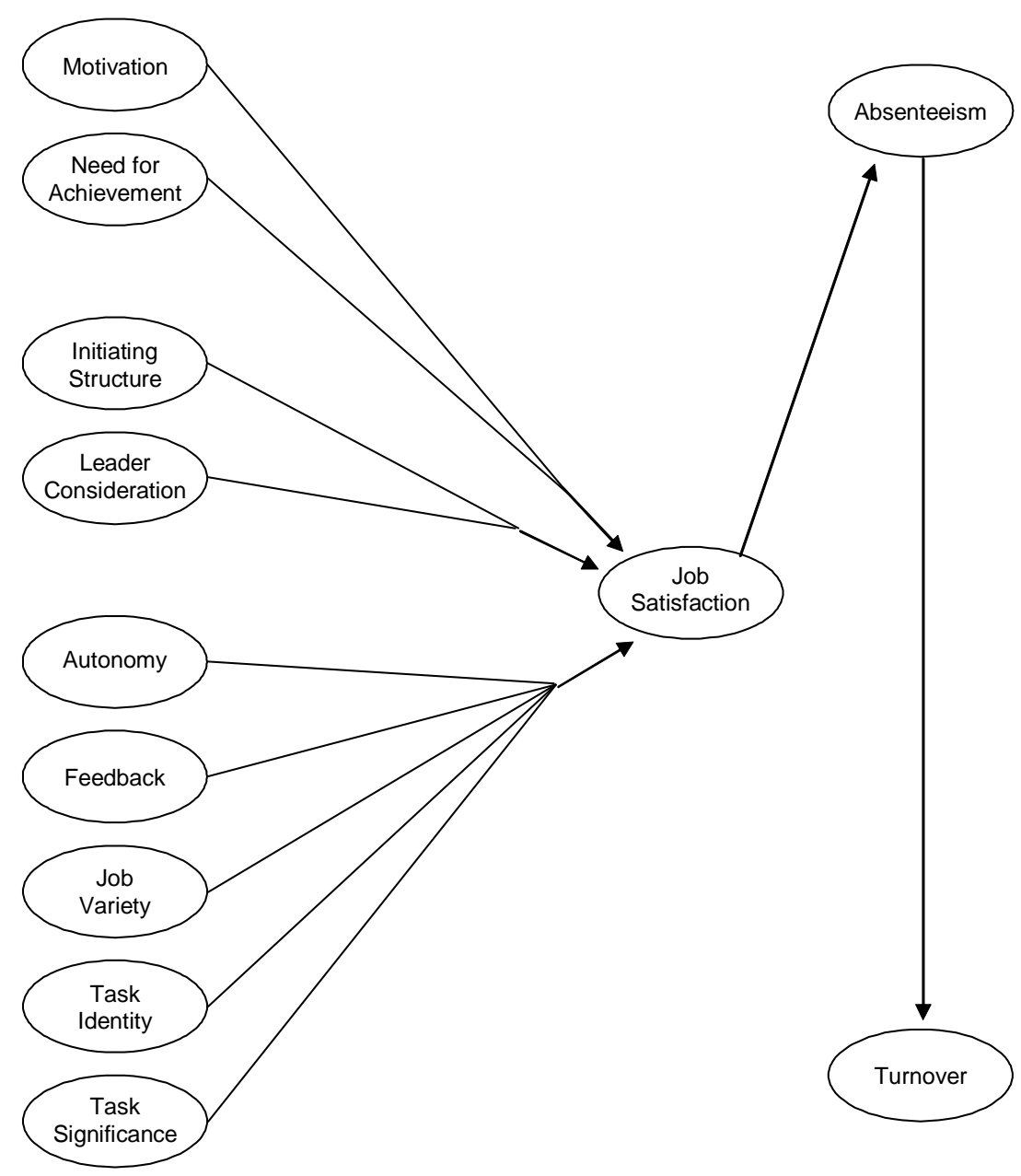

\section{Results}

The overall assessment of the fit of a model required careful consideration. It is appropriate to analyze the fit of a model with multiple indicators that represent its significance. This allowed for the compensation of weaknesses that are inherent in some fit measures and not others. Chi-square $\left(\chi^{2}\right)$ and the corresponding probability level examines the hypothesis that the predicted covariance matrix matches the sample covariance matrix in over-identified models (Bollen, 1989). The chi-square for this model indicated a good fit $\left(\chi^{2}=24.77, p>.05\right)$. The Goodness of Fit Index (GFI) measures the relative amount of the variance and covariance that are jointly accounted for by the model (Chalykoff \& Kochran, 1989). Unlike $\chi^{2}$, this measure is independent of sample size and also robust to nonnormality. There is no known 
statistical distribution for this test, but Bentler and Bonett (1980) provided a rule of thumb of .90 or greater. The GFI for this study was quite acceptable with a value of .99. Finally, the Critical N (CN) measure represents the size of the sample that would be required to make the observed difference between the predicted covariance matrix and the sample covariance matrix just significant at a typical critical level of significance (Hoetler, 1983). Hoetler (1983) viewed Critical N's of 200 or more as the appropriate cutoff point. The Critical $\mathrm{N}$ for this study was very high at 617.07. Overall, these three test statistics indicated that the overall fit of the model was more than adequate or acceptable. The five previously discussed research propositions that were discussed earlier were examined in light of the supported model. The supported model is shown in Figure 2.

Figure 2 Supported Model Metric (Standardized) Path Coefficients

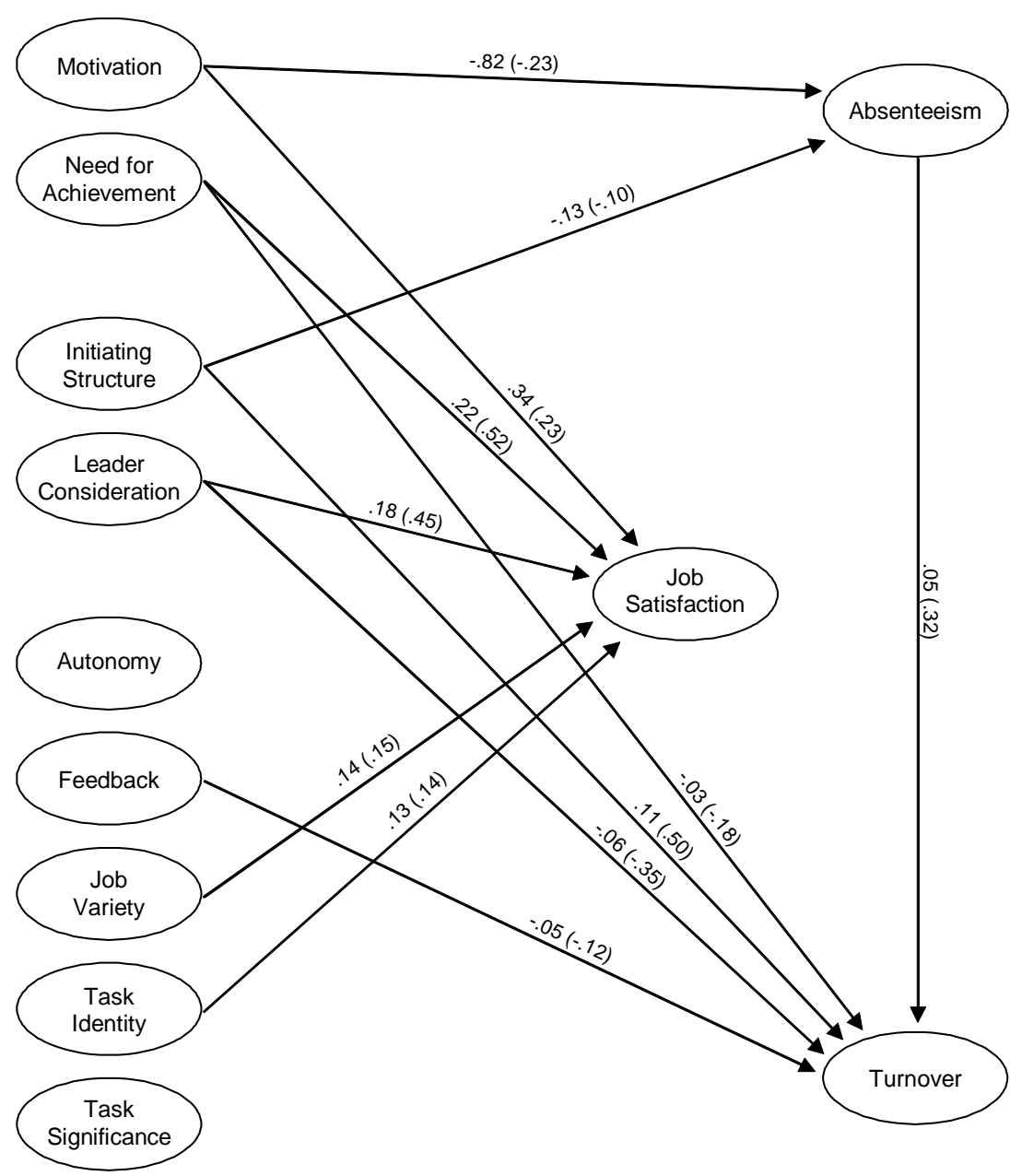




\section{Hypothesis 1}

This hypothesis was confirmed in the model. Two of the individual dimensions of task characteristics were significant. Job variety $(\gamma=.14, \mathrm{t}=3.22, \mathrm{p}<.05)$ and task identity $(\gamma=.13, \mathrm{t}=3.10, \mathrm{p}<.05)$ were significant antecedents to job satisfaction. This gave support, though somewhat limited, for the task characteristics approach. There was also evidence for the social information processing approach in that leader consideration $(\gamma=.18, t=10.92, p<.05)$ was a significant antecedent to job satisfaction. However, the most impressive support was for the dispositional approach. There was a significant and strong direct impact from both need for achievement $(\gamma=.22, \mathrm{t}=12.91, \mathrm{p}<.05)$ and motivation $(\gamma=.34, \mathrm{t}=4.74, \mathrm{p}<.05)$ as predictors of satisfaction. Overall, the results gave support for the combined or dual-attachment approach as all three of the viewpoints were involved in job satisfaction. These three sets of variables functioned as powerful predictors of job satisfaction. They explained approximately $78 \%$ of job satisfaction's variance.

\section{Hypothesis 2}

This hypothesis was confirmed in the model. The standardized direct effects (path coefficients signified with asterisk) from both of the dispositional variables were significant. Need for achievement was the strongest predictor of job satisfaction $\left(\gamma^{*}=.52, \mathrm{t}=12.91, \mathrm{p}<.05\right)$, and motivation was also a very good predictor $\left(\gamma^{*}=.23, \mathrm{t}=4.74, \mathrm{p}<.05\right)$. The only other predictor with an impact approaching the dispositional variables was leader consideration $\left(\gamma^{*}=.45, \mathrm{t}=\right.$ $10.92, \mathrm{p}<.05)$; however, leader initiating structure was not significant. As mentioned earlier, there were only two significant task characteristics, job variety and task identity. Autonomy, feedback, and task significance were not significant predictors. Additionally, the direct effects from job variety and task identity were relatively small compared to the effects from the dispositional variables $\left(\gamma^{*}=.15, \mathrm{t}=3.22, \mathrm{p}<.05 ; \gamma^{*}=.14, \mathrm{t}=3.10, \mathrm{p}<.05\right)$. Overall, the dispositional variables had the strongest impact of any of the variables on job satisfaction.

\section{Hypotheses 3 And 4}

These hypotheses were not confirmed in the model. Job satisfaction did not have a significant direct effect on absenteeism. Consequently, its indirect effects on turnover were not significant. Only two variables were significant predictors of absenteeism across samples. Leader initiating structure $\left(\gamma^{*}=-.10, \mathrm{t}=-.21, \mathrm{p}<.05\right)$ and motivation $\left(\gamma^{*}=\right.$ $.23, \mathrm{t}=-4.42, \mathrm{p}<.05)$ had significant standardized path coefficients. This model did little to define job satisfaction's role in withdrawal progression. Overall, the combined set of variables explained only $6 \%$ of the variance in absenteeism. It was apparent that employee absenteeism was influenced by other variables not included in the present model.

\section{Hypothesis 5}

This hypothesis was confirmed by the results. Absenteeism had a significant positive direct effect on turnover $\left(\beta^{*}=.32, \mathrm{t}=7.79, \mathrm{p}<.05\right)$. This gave evidence to a progression of withdrawal behaviors. Though absenteeism was a relatively good predictor of turnover, the best predictor was leader initiating structure $\left(\gamma^{*}=.50, \mathrm{t}=7.63, \mathrm{p}<.05\right)$. Other significant antecedents to turnover were leader consideration $\left(\gamma^{*}=-.35, \mathrm{t}=-5.28, \mathrm{p}<.05\right)$, need for achievement $\left(\gamma^{*}=\right.$ $.18 \mathrm{t}=-3.75, \mathrm{p}<.05)$, and feedback $\left(\gamma^{*}=-.12, \mathrm{t}=-2.27, \mathrm{p}<.05\right)$. The model itself did more than an adequate job in predicting turnover $\left(\mathrm{R}^{2}=.301\right)$.

The results emphasized the importance of leadership in the turnover process. Leaders appeared to initiate more structure to absent employees and potential separations in an attempt to possibly bring them back in line. Additionally, supervisors appear to also employ more of a softer approach by giving them more of their consideration and feedback. A possible explanation could be the concept of functional versus dysfunctional turnover (Dalton, Tudor, \& Krackhardt, 1982) and voluntary and unvoluntary turnover (Campion \& Mitchell, 1986). It is possible that initiating structure would be used for functional turnover and/or unavoidable turnover (i.e. eliminating a poor worker) and the consideration would be used in the case of dysfunctional turnover and/or avoidable turnover. The significance of the dispositional variable, need for achievement, likely reflected that individuals with a higher need for achievement were possibly more apt to leave an organization that did not give them the opportunity to satisfy that need. 


\section{Discussion And Suggestions For Future Research}

The integrated methodologies address not only causality, but also add external validity. Job design, leadership, and dispositions are all involved in job satisfaction to varying degrees and are important factors. The dispositional approach cannot be dismissed in its impact on job satisfaction. To the contrary, across samples, it is the most important factor. This coincides with other recent studies supporting dispositions and their impact on individual behavior in the workplace (Judge \& Larsen, 2001).

Future applied research could examine the influence of dispositional factors that are related to dimensions of job success as an integral part of an organization's hiring process (i.e. selection procedures). The utilization of paper and pencil instruments, instead of projective tests, could be employed due to validity concerns of projective measures. Hough, Eaton, Dunnette, Kamp, and McCloy (1990) indicated that personality traits have adequate validity and utility in selection procedures, even measures based on perception and judgment. The impact that dispositional factors have on other affective responses to the work setting such as organizational commitment, organizational citizenship behaviors, and job involvement are areas for further examination. The inclusion of these variables in more comprehensive frameworks where concurrent impact can be examined would seem appropriate.

Job satisfaction does not have a significant impact on the withdrawal behaviors of absenteeism or turnover. The model itself does poorly in explaining absenteeism. It accounts for only $6.3 \%$ of the variance in absenteeism. Although job satisfaction has been found to have a relationship with absenteeism in previously mentioned meta-analyses, the direct relationship between these variables disappears in a comprehensive path model. The exact role that job satisfaction plays in absenteeism needs better explication. Job satisfaction may serve as a moderator variable in the process. The inclusion of other theorized influences from absenteeism models examining job satisfaction as a possible moderator would seem appropriate. Additionally, the impact of organizational commitment needs to be examined in relation to absenteeism. It is possible that organizational commitment serves as a mediator between job satisfaction and withdrawal behaviors. In essence, continued job dissatisfaction will lower a worker's commitment to the organization and this will precipitate withdrawal behaviors.

The model indicates that leaders are strongly involved in turnover. But it appears that their involvement in the process is mostly reactive as opposed to proactive. The patterns and signs of direct and indirect effects point to the conclusion that supervisors react to possible separation with more structure, consideration, and feedback. Job satisfaction does not have a direct or indirect impact on the process. Future research should examine this leadership relationship in association with avoidable/ unavoidable turnover and functional/dysfunctional turnover. It would seem that initiating structure would be more related to possible functional or involuntary turnover (i.e. dismissal), and consideration and feedback would be involved in functional or voluntary turnover (i.e. the possible loss of a good employee). The addition of organizational commitment concurrently with job satisfaction could significantly improve turnover models. Job satisfaction may interact with commitment to impact withdrawal behaviors. Organizational commitment is related to previously discussed investments that a worker builds in the firm (for example - promotions, salary, friendships, etc.) that makes it difficult for the employee to leave the organization. This would spell out a process where commitment is related to turnover, and satisfaction's impact is indirect through its relationship with organizational commitment.

\section{References}

1. $\quad$ Adams, J.S., "Inequity in Social Exchange," In L. Berkowitz (Ed.), Advances in Experimental Psychology, Vol. 2, Academic Press, New York, 1965.

2. Benson, P.G. and S.B. Pond, “An Investigation of the Process of Employee Withdrawal," Journal of Business and Psychology, Vol. 1, pp. 218-229, 1987.

3. Bentler, P.M. and D.G. Bonett, "Significance Tests and Goodness-of-Fit in the Analysis of Covariance Structures," Psychological Bulletin, Vol. 88, pp. 588-600, 1980.

4. Bluedorn, A.C., "A Unified Model of Turnover from Organizations," Human Relations, Vol. 35, pp. 135-153, 1982.

5. $\quad$ Bollen, K.A., Structural Equations with Latent Variables, Wiley, New York, 1989. 
6. Brief, A.P. and R.J. Aldag, "The Job Characteristics Inventory: An Examination,” Academy of Management Journal, Vol. 21, pp. 659-670, 1978.

7. Brooke, P.P. and J.L. Price, "The Determinants of Employee Absenteeism: An Empirical Test of a Causal Model," Journal of Occupational Psychology, Vol. 62, pp. 1-19, 1989.

8. Bhuian, S.N., E.S. Al-Shammari, \& O.A. Jeffri, "Organizational Commitment, Job Satisfaction and Job Characteristics: An Empirical Study of Expatriates in Saudi Arabia," International Journal of Commerce \& Management, Vol. 6 (3/4), pp. 57-80, 1996.

9. Bhuian, S.N. and B. Menguc, "An Extension and Evaluation of Job Characteristics, Organizational Commitment and Job Satisfaction in an Expatriate, Guest Worker, Sales Setting," The Journal of Personal Selling \& Sales Management, Vol. 22 (1), pp. 1-11, 2002.

10. Campion, M.A., and M.M. Mitchell, "Management Turnover: Experiential Differences Between Former and Current Managers," Personnel Psychology, Vol. 39, pp. 57-69, 1986.

11. Chadwick-Jones, J.K., N. Nicholson, \& C. Brown, The Social Psychology of Absenteeism, Praeger, New York, 1982.

12. Chalykoff, J. and T.A. Kochran, "Computer-Aided Monitoring: Its Influence on Employee Job Satisfaction and Turnover," Personnel Psychology, Vol. 42, pp. 807-834, 1989.

13. Clegg, C.W., "Psychology of Employee Lateness, Absence, and Turnover: A Methodological Critique and an Empirical Study,” Journal of Applied Psychology, Vol. 68, pp. 88-101, 1983.

14. Connolly, J.J. and C. Viswesvaran, "The Role of Affectivity in Job Satisfaction: A Meta-Analysis, Personality and Individual Differences, Vol. 29, pp. 265-281, 2000.

15. Cooper, H.M., Integrating Research: A Guide for Literature Reviews, Sage, Newbury Park, California, 1989.

16. Costa, P.T. and R.R. McCrae, "Influence of Extraversion and Neuroticism on Subjective Well-Being: Happy and Unhappy People," Journal of Personality and Social Psychology, Vol. 38, pp. 668-678, 1994.

17. Cotton, J.L. and J.M. Tuttle, "Employee Turnover: A Meta-Analysis and Review with Implications for Research," Academy of Management Review, Vol. 11, pp. 55-70, 1986.

18. Davis-Blake, A. and J. Pfeffer, "Just a Mirage: The Search for Dispositional Effects in Organizational Research," Academy of Management Review, Vol. 14, pp. 385-400, 1989.

19. Dalton, D.R., W.D. Tudor, \& D. Krackhardt, "Turnover Overstated: The Functional Taxonomy," Academy of Management Review, Vol. 7, pp. 117-123, 1982.

20. de Vries, R.E., R.A. Roe, T.C.B. Taillieu, "Need for Supervision: Its Impact on Leadership Effectiveness,” The Journal of Applied Behavioral Science, Vol. 34 (4), pp. 486-501, 1998.

21. Dubinsky, A.J., F.J. Yammarino, M.A. Jolson, \& W.D. Spangler, "Transformational Leadership: An Initial Investigation in Sales Management," Journal of Personal Selling \& Sales Management, Vol. 6, pp. 17-31, 1995.

22. Eby, L.T., D.M. Freeman, M.C. Rush, \& C.E. Lance, "Motivational Bases of Affective Organizational Commitment: A Partial Test of an Integrative Theoretical Model," Journal of Occupational and Organizational Psychology, Vol. 72 (4), pp. 163-483, 1999.

23. Farrell, D. and C.L. Stamm, "Meta-Analysis of the Correlates of Employee Absence," Human Relations, Vol. 41, pp. 211-227, 1988.

24. Fleishman, E.A., "The Description of Supervisory Behavior," Journal of Applied Psychology, Vol. 37, pp. 1-6, 1953.

25. Graen, G.B., "Role-Making Processes Within Complex Organizations," In M. D. Dunnette (Ed.), Handbook of Industrial and Organizational Psychology, Rand-McNally, Chicago, 1976.

26. Graen, G.B. and S. Ginsburgh, "Job Resignation as a Function of Role Orientation and Leader Acceptance: A Longitudinal Investigation of Organizational Assimilation," Organizational Behavior and Human Performance, Vol. 19, pp. 1-17, 1977.

27. Greenberger, D.B., S. Strasser, L.L. Cummings, \& R.B. Dunham, "The Impact of Personal Control on Performance and Satisfaction,” Organizational Behavior and Human Decision Processes, Vol. 43, pp. 29-51, 1989.

28. Griffin, R.W., "Objective and Social Sources of Information in Task Redesign: A Field Experiment," Administrative Science Quarterly, Vol. 28, pp. 184-200, 1983.

29. Griffin, R.W., T.S. Bateman, S.J. Wayne, \& T.C. Head, “Objective and Social Factors as Determinants of Task Perceptions and Responses: An Integrated Perspective and Empirical Investigation," Academy of Management Journal, Vol. 30, pp. 501-523, 1987. 
30. Gupta, N. and G.D. Jenkins, “Absenteeism and Turnover: Is There a Progression?” Journal of Management Studies, Vol. 19, pp. 395-412, 1982.

31. Hackett, R.D. and R.M. Guion, "A Reevaluation of the Absenteeism-Job Satisfaction Relationship," Organizational Behavior and Human Decision Processes, Vol. 35, pp. 340-381, 1985.

32. Hackman, J.R. and E.E. Lawler, "Employee Reactions to Job Characteristics.” Journal of Applied Psychology, Vol. 55, pp. 259-286, 1971.

33. Hackman, J.R. and G.R. Oldham, "Development of the Job Diagnostic Survey,” Journal of Applied Psychology, Vol. 60, pp. 159-170, 1975.

34. Hayduk, L.A., Structural Equation Modeling with Lisrel, Essentials and Advances, Johns Hopkins University Press, Baltimore, Maryland, 1987.

35. Herzberg, F., B. Mauser, R.O. Peterson, \& D.F. Capwell, Job Attitudes: Review of Research and Opinion, Psychological Service of Pittsburgh, Pittsburgh, Pennsylvania, 1957.

36. Hoetler, J.W., "The Analysis of Covariance Structures: Goodness of Fit Indices," Sociological Methods and Research, Vol. 11, pp. 325-344, 1983.

37. Hogan, E.A. and D.A. Martell, "A Confirmatory Structural Equations Analysis of the Job Characteristics Model,” Organizational Behavior and Human Decision Processes, Vol. 39, pp. 242-263, 1987.

38. Hollenbeck, J.R. and E.M. Whitener, "Reclaiming Personality Traits for Personal Selection: Self-Esteem as an Illustrative Case,” Journal of Management, Vol. 14, pp. 81-91, 1988.

39. Hough, L.M., N.K. Eaton, M.D. Dunnette, J.D. Kamp, \& R.A. McCloy, "Criterion-Related Validities of Personality Constructs and the Effect of Response Distortion on Those Validities," Journal of Applied Psychology, Vol. 75, pp. 581-595, 1990.

40. Johnston, M.W., P.R. Varadarajan, C.M. Futrell, \& J. Sager, "The Relationship Between Organizational Commitment, Job Satisfaction, and Turnover Among New Salespeople,” Journal of Personal Selling and Sales Management, Vol. 7, pp. 29-38, 1987.

41. Jones, E., D.M. Kantak, C.M. Futrell, \& M.W. Johnston, "Leader Behavior, Work Attitudes, and Turnover of Salespeople: An Integrative Study,” The Journal of Personal Selling \& Sales Management, Vol. 16 (2), pp. 1323, 1996.

42. Joreskog, K. and D. Sorbom, Lisrel 8: Structural Equation Modeling with Simplis Command Language, Lawrence Erlbaum Associates Publishers, Hillsdale, New Jersey, 1993.

43. Judge, T.A. and R.J. Larsen, "Dispositional Affect and Job Satisfaction: A Review and Theoretical Extension," Organizational Behavior and Human Decision Processes," Vol. 86 (1), pp. 67-98, 2001.

44. Kerr, S. and J.M. Jermier, "Substitutes for Leadership: Their Meaning and Measurement," Organizational Behavioral and Human Performance, Vol. 22, pp. 375-403, 1978.

45. Landeweed, J.A. and N.P.G. Bouman, “The Effect of Work Dimensions and Need for Autonomy on Nurses' Work Satisfaction and Health,” Journal of Occupational and Organizational Psychology, Vol. 67, pp. 207-217, 1994.

46. Leigh, J.H., G.H. Lucas, \& R.W. Woodman, "Effects of Perceived Organizational Factors on Role Stress-Job Attitude Relationships,” Journal of Management, Vol. 14, pp. 41-58, 1988.

47. Locke, E.A., "The Nature and Causes of Job Satisfaction,” In Marvin D. Dunnette (Ed.), Handbook of Industrial and Organizational Psychology, Rand-McNally, Chicago, Illinois, 1976.

48. Lu, Luo, "Work Motivation, Job Stress, and Employees' Well-Being,” Journal of Applied Management Studies, Vol. 9 (1), pp. 61-72, 1999.

49. Mannheim, B., Y. Baruch, \& J. Tal, “Alternative Models for Antecedents and Outcomes of Work Centrality and Job Satisfaction of High-Tech Personnel,” Human Relations, Vol. 50 (12), pp. 1537-1562, 1997.

50. Mobley, W.H., R.W.Griffeth, H.H. Hand, B.M. Meglino, "Review and Conceptual Analysis of the Employee Turnover Process," Psychological Bulletin, Vol. 83 (3), pp. 493-522, 1979.

51. Mowday, R.T., L.W. Porter, \& R.M. Steers, Employee-Organizational Linkages: The Psychology of Commitment, Absenteeism, and Turnover, Basic Books, New York, 1982.

52. Pedhazur, E.J., Multiple Regression in Behavior Research, Explanation and Prediction, Holt, Rinehart, \& Winston, New York, 1982.

53. Pfeffer, J., Organizations and Organizational Theory, Ballinger Publishing Company, Cambridge, Massachusetts, 1982.

54. Price, J.L., The Study of Turnover, Iowa State University Press, Ames, Iowa, 1977. 
55. Price, J.L. and C.W. Mueller, "A Causal Model of Turnover for Nurses," Academy of Management Journal, Vol. 24, pp. 543-565, 1981.

56. Reiner, M.D. and J. Zhao, "The Determinants of Job Satisfaction Among United States Air Force Security Police," Review of Public Personnel Administration, Vol. 19 (3), pp. 5-18, 1999.

57. Rosse, J.G., "Relations Between Lateness, Absence, and Turnover: Is There a Progression of Withdrawal," Human Relations, Vol. 41, pp. 517-531, 1988.

58. Salancik, G.R. and J. Pfeffer, "A Social Information Processing Approach to Job Attitudes and Task Design," Administrative Science Quarterly, Vol. 23, pp. 224-253, 1978.

59. Savery, L.K., "The Congruence Between the Importance of Job Satisfaction and the Perceived Level of Achievement," The Journal of Management Development, Vol. 15 (6), 18-27, 1996.

60. Schonfeld, I.S., "An Updated Look at Depressive Symptoms and Job Satisfaction in First-Year Women Teachers," Journal of Occupational and Organizational Psychology, Vol. 73, pp. 363-371, 2000.

61. Scott, K.D. and G.S. Taylor, "An Examination of Conflicting Findings on the Relationship Between Job Satisfaction and Absenteeism: A Meta-Analysis," Academy of Management Journal, Vol. 28, pp. 599-612, 1985.

62. Seers, A. and G.B. Graen, "The Dual Attachment Concept: A Longitudinal Investigation of the Combination of Task Characteristics and Leader-Member Exchange," Organizational Behavior and Human Performance, Vol. 33, pp. 283-306, 1984.

63. Simmons, B.L., D.L. Nelson, \& L.J. Neal, "A Comparison of the Positive and Negative Work Attitudes of Home Healthcare and Hospital Nurses," Healthcare Management Review, Vol. 26 (3), pp. 63-74, 2001.

64. Sims, H.P., A.D. Szilagyi, \& R.T. Keller, "The Measurement of Job Characteristics," Academy of Management Journal, Vol. 19, pp. 195-224, 1976.

65. Staw, B.M., N.E. Bell, \& J.A. Clausen, “The Dispositional Approach to Job Attitudes: A Lifetime Longitudinal Test,” Administrative Science Quarterly, Vol. 31, pp. 56-77, 1986.

66. Staw, B.M. and J. Ross, "Stability in the Midst of Change: A Dispositional Approach of Job Attitudes," Journal of Applied Psychology, Vol. 70, pp. 469-480, 1985.

67. Steel, R.P. and J.R. Rentsch, "The Dispositional Model of Job Attitudes Revisited: Findings of a 10-Year Study, Journal of Applied Psychology, Vol. 82 (6), pp. 873-879, 1997.

68. Steel, R.P., G.S. Shane, \& R.W. Griffeth, "Correcting Turnover Statistics for Comparative Analysis," Academy of Management Journal, Vol. 33, pp. 179-187, 1990.

69. Steers, R.M. and D. Braunstein, “A Behaviorally-Based Measure of Manifest Needs in Work Settings,” Journal of Vocational Behavior, Vol. 9, pp. 251-266, 1976.

70. Stogdill, R.M., Manual for the Leader Behavior Description Questionnaire-Form XII, Bureau of Business Research, Ohio State University, Columbus, Ohio, 1963.

71. Tett, R.P. and J.P. Meyer, “Job Satisfaction, Organizational Commitment, Turnover Intention, and Turnover: Path Analyses Based on Meta-Analytic Findings,” Personnel Psychology, Vol. 46, pp. 259-293, 1993.

72. Tiegs, R.B., L.E. Tetrick, \& Y. Fried, "Growth Need Strength and Context Satisfaction as Moderators of the Relations of the Job Characteristics Model," Journal of Management, Vol. 18, pp. 575-593, 1992.

73. Ting, Y., "Analysis of Job Satisfaction of the Federal White-Collar Work Force: Findings from the Survey of Federal Employees," American Review of Public Administration, Vol. 26 (4), pp. 439-456, 1996.

74. Vroom, V.H., Work and motivation, Wiley, New York, 1964.

75. Walsh, J.T., T.D. Taber, \& T.A. Beehr, “An Integrated Model of Perceived Job Characteristics,” Organizational Behavior and Human Performance, Vol. 25, pp. 252-267, 1980.

76. Watson, C.J., "An Evaluation of Some Aspects of the Steers and Rhodes Model of Employee Attendance," Journal of Applied Psychology, Vol. 66, pp. 385-389, 1981.

77. White, S.E. and T.R. Mitchell, "Job Enrichment Verses Social Cues: A Comparison and Competitive Test," Journal of Applied Psychology, Vol. 64, pp. 1-9, 1979.

78. Wolpin, J. and R.J. Burke, "Relationships Between Absenteeism and Turnover: A Function of the Measures?" Personnel Psychology, Vol. 38, pp. 57-75, 1985.

79. Zeffane, R., "Job Satisfaction and Its Implications for Work Redesign: Findings from Australia," International Journal of Comparative Sociology, Vol. 1-2, pp. 137-141, 1994. 
Notes 